\title{
TUTELA ANTECIPADA E A (IN) EXISTÊNCIA DE COISA JULGADA
}

Nathalia Dutra da Rocha Jucá e Mello ${ }^{1}$ Bárbara Elaine Carneiro de Moraes²

\section{RESUMO}

Conforme cediço, a concessão de tutela antecipada é oriunda, via de regra, de uma cognição sumária do magistrado e, portanto, passível de revogação posteriormente. Contudo, há previsão no atual Código de Processo Civil, art. 273, §6º, em que "a tutela antecipada também poderá ser concedida quando um ou mais dos pedidos cumulados, ou parcela deles, mostrar-se incontroverso". Nesta premissa, iniciam-se discussões acerca da possibilidade ou não de formação de coisa julgada em decorrência do dispositivo legal supra citado. Partindo-se dos pressupostos que regem a antecipação de tutela, serão analisadas as posições divergentes acerca formação ou não de coisa julgada para o caso de antecipação de tutela em pedido incontroverso. Tais posições serão analisadas com respaldo na doutrina e legislação pátria, bem como analise de caso em recente julgado do Superior Tribunal de Justiça - STJ.

PALAVRAS-CHAVE: TUTELA ANTECIPADA. COISA JULGADA. COGNIÇÃO SUMÁRIA. INCONTROVERSO.

\footnotetext{
${ }^{1}$ Especialista em Direito Processual pela Universidade Federal de Juiz de Fora. Pós graduanda em Direito Constitucional pela Faculdade Damásio de Jesus. Advogada.

${ }^{2}$ Professora do Curso de Direito das Faculdades Integradas Vianna Junior. Especialista em Direito Processual Civil. Advogada.
} 


\section{VIANNAS SAPIENS}

edição especial
iz de Fora - 2014

\section{INTRODUÇÃO}

Um dos maiores valores que o integram o nosso sistema processual, é a segurança jurídica, representada pela coisa julgada.

Nesse sentido, certo é que vários fatores influenciam na efetiva prestação da tutela jurisdicional pleiteada, causando, por vezes, a demora na entrega do bem jurídico tutelado.

O exercício pleno do contraditório e da ampla defesa, a busca da verdade com produção de provas, e a necessidade de o magistrado exercer sua cognição exauriente, alcançando o objetivo do processo - instrumento da pacificação social inevitavelmente ocasionam esta demora.

Contudo, em determinadas situações, não há possibilidade da utilização da cognição plena e exauriente pelo magistrado, vez que necessitam de uma tutela sumária urgente, em lapso temporal breve. Nesses casos, a morosidade poderia gerar danos irreparáveis ao seu requerente e ao curso regular do processo com a prestação jurisdicional.

Dessa forma, o legislador criou instrumentos processuais aptos a fornecer um resultado rápido e diligente aos casos, adaptando-se às realidades sociais que o provoca, nas quais, muitas vezes, não podem esperar o tempo necessário para o exercício de cognição exauriente.

As Tutelas de Urgência se enquadram nas tutelas baseadas em cognição sumária, são elas: tutelas cautelares e tutelas antecipatórias (nos casos de serem concedidas quando há risco iminente de prejuízo irreparável).

Via de regra as decisões provenientes de cognição sumária e, portanto, formadas em juízo de probabilidade e de maneira menos aprofundada, não formam coisa julgada material, já que para tanto é necessário precisar a existência ou não de determinado direito material.

Em entendimento contrário, conforme se estudará adiante, existem posições que defendem a formação de coisa julgada material em decorrência de decisões firmadas com base em cognição sumária, em análise estrita do art. 273, §6º do Código de Processo Civil. 
Nesta linha de pensamento, o presente estudo pretende explicitar as principais características da tutela antecipada e seus efeitos, dentre eles, a formação ou não da coisa julgada

\section{TUTELAS DE URGÊNCIA: tutela cautelar x tutela antecipada}

A tutela jurisdicional exercida poderá ser provisória, quando formada com base em cognição sumária, ou definitiva, quando formada com base na cognição exauriente, com profunda análise do processo e formação de coisa julgada material, já que produz efeitos imutáveis (DIDIER JR., 2012, p. 468 e 469).

Daí a criação da Tutela Cautelar, que se trata de uma tutela não-satisfativa que visa a assegurar, conservar o direito reclamado, amenizando os malefícios do tempo para sua futura satisfação. É, portanto, instrumental e temporária (possui eficácia limitada, o que não exclui sua definitividade já que tem a decisão pautada em cognição exauriente e, então, está apta a se tornar imutável).

Uma vez proferida a decisão cautelar e precluso o direito recursal, a mesma não mais poderá ser alterada ou revogada.

Dessa forma, conclui-se que toda tutela definitiva, satisfativa ou não (cautelar), será concedida em decorrência de uma cognição exauriente e predisposta à coisa julgada.

Lado outro, a tutela jurisdicional provisória é aquela que acarreta satisfação imediata, ou seja, dá pronta eficácia à tutela definitiva. Obviamente, por ser provisória, precisará posteriormente ser ratificada e substituída por uma tutela definitiva.

Em razão do uso indiscriminado e distorcido do processo cautelar na tentativa de obter tutela que só poderia ser concedida ao fim do processo, ou seja, proviória, o legislador se viu obrigado a inserir novas regras para a "antecipação de tutela" no Código de Processo Civil, arts. 273 e 461 (MARINONI e ARENHART, 2012). 
Nestes casos o convencimento do magistrado se forma por meio de cognição sumária e precária, já que sua decisão pode ser revogada a qualquer tempo e, por consequência, não estará apta à formação de coisa julgada.

Em linhas gerais observamos, pois, que a tutela antecipada dá eficácia imediata à tutela definitiva; poderá ser satisfativa ou cautelar; prescindirá de prova inequívoca de verossimilhança do direito; pode pressupor urgência ou não; é provisória e precária. Já a tutela cautelar assegura futura eficácia de tutela definitiva; será sempre conservativa (cautelar); a prova será a simples verossimilhança do direito acautelado; sempre pressupõe urgência; é definitiva e predisposta à imutabilidade (DIDIER, 2012, p. 472).

$\mathrm{Na}$ prática, essa distinção perdeu boa parte de sua importância, haja vista a possível "fungibilidade" prevista pelo art. $273, \S 7^{\circ}$ do CPC.

Leciona com maestria sobre o assunto Luiz Guilherme Marinoni (2012)

O $\S 7^{\circ}$ do art. 273 alude a uma ideia de fungibilidade, e esta pressupõe duas espécies de providências que possam ser racional e justificadamente confundidas, e, assim, uma dúvida objetiva e razoável.

Frise-se, não obstante, que 0 $\$ 7^{\circ}$ do art. 273 , ao admitir a confusão entre as tutelas cautelar e antecipatória, sublinha a distinção entre ambas. Isto por uma razão de lógica elementar: somente coisas distintas podem ser confundidas.

Portanto, vale ressaltar que não se deve usar essa possibilidade para 'confundir' os dois institutos, sob pena de se rejeitar a previsão processual civil e suas reais intenções, bem como seus efeitos e consequências.

\subsection{Tutela antecipada é invariavelmente uma tutela de urgência?}

A tutela antecipada é, em regra, uma tutela de urgência. Contudo comporta exceções, senão vejamos.

Diz-se isto porque o art. 273, CPC, prevê duas possibilidades para a referida antecipação. 
Em seu inciso I é prevista a possibilidade de antecipação de tutela quando "haja fundado receio de dano irreparável ou de difícil reparação". Nesse caso, falase em urgência, não havendo maiores discussões.

Em seguida, no inciso II, há a previsão para o cabimento de antecipação de tutela "quando fique caracterizado o abuso de direito de defesa ou manifesto propósito protelatório do réu".

Especificamente nesta possibilidade prevista no inciso II do art. 273, CPC, não se fala em tutela de urgência. Aqui trata-se de uma tutela com caráter punitivo, rechaçando de plano a ma-fé e obstáculos criados ao andamento regular do processo, consagrando a modalidade de tutela de lealdade e seriedade processual.

Segundo Athos Gusmão Carneiro (2004)

(...) 0 art. 273, II, criou uma antecipação de tutela pura, desvinculada por pressupostos da urgência e do dano e ligada tão somente à ideia central de que a firme aparência do bom direito, exsurgente das alegações do autor, aliada à desvalia evidente, à falta de consistência na defesa apresentada pelo demandado, autorizam a satisfação antecipada a fim de que o (aparente) titular de um direito possa de imediato vê-lo (provisoriamente) incorporado ao seu patrimônio jurídico.

Na prática, vem sendo rara a incidência do dispositivo supra mencionado, já que existem outros instrumentos previstos em nosso digesto processual para combater a deslealdade processual e atos meramente protelatórios, inclusive com possibilidade se aplicar multas pecuniárias.

Na visão de Fredie Didier Jr. (2012)

o abuso de do direito de defesa ou o manifesto propósito protelatório do réu, em muitas situações, pode acabar conduzindo a um julgamento antecipado da lide e, não, a uma antecipação de tutela. Assim, a grande utilidade da antecipação de tutela, nesses casos, reside na possibilidade de afastar o efeito suspensivo da apelação, conferindo-se eficácia imediata à sentença.

Conclui-se, pois, que a tutela antecipada não será invariavelmente uma espécie de tutela de urgência em decorrência da disposição em seu inciso II, que externa caráter diverso. 


\section{VIANNASAPIENS}

edição especial
iz de Fora - 2014

\section{DA COISA JULGADA MATERIAL NAS TUTELAS ANTECIPATÓRIAS}

Conforme tratado anteriormente, a antecipação de tutela sugere conferir a efetivação da função jurisdicional, in casu, não como meio assecuratório, mas sim definitivo.

Parte dos doutrinadores, dentre eles Luiz Guilherme Marinoni (1998), afirma que não se antecipa a própria tutela, mas sim seus efeitos.

Nos casos em que a antecipação de tutela se tratar de tutela de urgência em razão do perigo da demora (art. 273, I, CPC), deverão estar presentes os pressupostos genéricos de prova inequívoca e virossimilhança das alegações, que conduzem o magistrado a um juízo de probabilidade sobre a credibilidade dos fatos narrados.

É indubitável que na antecipação de tutela há uma cognição sumária, e não exauriente.

Justamente por tal motivo é que, para assegurar o contraditório, ainda que a posteriori, é que a lei não admite que o juiz conceda a antecipação de tutela "quando houver perigo de irreversibilidade do provimento antecipado" $\left(\S 2^{\circ}\right)$.

Também neste sentido, o $4^{\circ}$ destaca que a medida poderá ser modificada ou revogada a qualquer tempo, desde que mediante decisão fundamentada, indicando as razões de seu convencimento.

Destaque-se que a decisão que conceder os efeitos da antecipação de tutela jamais poderá assumir efeito exauriente, já que deve guardar a possibilidade de retornar ao seu status a quo.

Certamente que tais ressalvas devem ser interpretadas de forma flexível, ponderando caso a caso o direito tutelado, sob pena da inutilização da medida e decisões teratológicas. Utiliza-se, nestes casos, o princípio da proporcionalidade.

Para minimizar os efeitos da irreversibilidade da decisão que concederá a tutela antecipada, poderá o juízo requerer caução para eventuais reparações, ainda que em pecúnia. 
Da decisão que conceder ou negar a antecipação de tutela, caberá Agravo de Instrumento, por ser, em regra, decisão interlocutória.

Vê-se, portanto, que ao se falar em precariedade, em cognição sumária, em possibilidade de revogação, não há como vislumbrar a coisa julgada nas tutelas antecipatórias.

Assim, conforme observado, é essa a posição que prevalece na doutrina pátria, defendida por doutrinadores renomados como, por exemplo, Fredie Didier e Luiz Guilherme Marinoni. Tal entendimento não parece restar maiores discussões já que cediço ser a tutela antecipatória revestida de fatores que colaboram com tal assertiva, como precariedade e reversibilidade.

Contudo, mister não olvidar que o art. 273, §6, CPC, prevê a possibilidade de o juiz conceder antecipação de tutela quando um ou mais dos pedidos mostrarem-se incontroversos e, neste espeque, inicia-se grande discussão acerca da coisa julgada, conforme se verá.

\subsection{Antecipação de tutela sob a ótica do art. $273, \S 6^{\circ}$ - resolução parcial do mérito da causa e a formação de coisa julgada}

O art. 273, $\S 6^{\circ}$ do CPC, incluído pela Lei $n^{\circ} 10.444 / 2002$, prevê que "a tutela antecipada também poderá ser concedida quando um ou mais dos pedidos cumulados, ou parcela deles, mostrar-se incontroverso".

Analisando o artigo, prima facie, a interpretação é clara quanto ao fato de o mesmo ser um dos tipos de resolução parcial de mérito, conforme estado do processo, pelo magistrado, quando atendido alguns requisitos, neste caso, quando um ou mais dos pedidos restar incontroverso.

Contudo, tal interpretação não é unanime.

A priori, merece destaque a origem do referido dispositivo, que teve como base a obra do doutrinador Luiz Guilherme Marinoni (1998), na qual estudou 
hipóteses de antecipação de tutela nos casos abuso do direito de defesa. Ainda, seguia a linha de raciocínio no sentido de que, havendo possibilidade de se julgar antecipadamente a lide, com fulcro no art. 330 do CPC, tal decisão, decidindo parcialmente algum dos pedidos, estaria revestida pela coisa julgada, já que para ocorrência desta situação, seria necessária a cognição exauriente pelo juízo.

Hodiernamente parte da doutrina ainda sustenta essa posição, como Fredie Didier (2012), afirmando que tal previsão legal, na verdade, consta como um erro "topográfico"; significa afirmar que para real utilidade do dispositivo, o mesmo não deveria constar no título que abrange a antecipação de tutela, mas naquele em que dispõe sobre modalidade de julgamento conforme o estado do processo.

Entende-se que, nesta hipótese, não há tutela provisória, já que não se trata de uma tutela de urgência (vide art.273, II) e, assim, não é caracterizada pela sumariedade da cognição ou da necessidade de reversibilidade.

A natureza jurídica deste artigo, considerando-se tratar de "equivoco topográfico", não é de tutela antecipada, e sim de resolução parcial do mérito.

Seus requisitos seriam diversos ao da tutela antecipatória, bastando que seja verificada a incontroversa de um ou mais pedidos, sem necessidade de dilação probatória, prova inequívoca, verossimilhança das alegações e fundado receio de dano. Estaríamos diante de um fracionamento do julgamento, com decisão interlocutória definitiva, capaz de ensejar a coisa julgada e passível de execução provisória.

Sendo assim, a decisão fundada no $\$ 6^{\circ}$ do artigo ora estudado, teria respaldo em cognição exauriente e revestida de definitividade, pois, para essa corrente doutrinária, interpretação contrária seria o mesmo que inutilizar e tornar ineficaz na prática tal dispositivo.

Lado outro, conforme se depreende, sendo possível o exercício de cognição exauriente no caso previsto pelo art. 273, $\S 6^{\circ}$, CPC, este restaria totalmente contraditório com a probabilidade exigida no caput do artigo e demais previsões pertinentes à matéria. 
Seguindo esse raciocínio, a posição contrária (NEVES, 2013) se firma na seara de que, se fosse a intenção do legislador a formação de coisa julgada nos casos em que há decisão parcial dos pedidos incontroversos, tal previsão não constaria como espécie de tutela antecipada.

Se assim o fez, foi exatamente para subordiná-la à possibilidade de ser revogada, devendo a resolução de mérito ser efetuada nos moldes especificamente previstos para tanto.

Além disso, outro argumento bastante conciso acerca da impossibilidade de coisa julgada na antecipação dos efeitos da tutela acerca de um ou mais pedidos, refere-se ao fato de que, apresentada contestação / fatos novos, o magistrado, de forma fundamentada, poderá alterar seu juízo de admissibilidade. Ou seja, se seguirmos a linha de que há formação de coisa julgada, isso não poderia ocorrer, acarretando, por certo, prejuízos a um dos litigantes desfavorecido com tal decisão.

Percebe-se que existem duas correntes, conforme demonstrado alhures, com argumentos bastante sólidos sobre a natureza jurídica do artigo 273, §6ํㅡ e sua capacidade ou não de formar a coisa julgada.

\subsubsection{Do pedido incontroverso}

Um dos motivos que geram tanta polêmica e discussão acerca da possibilidade da coisa julgada ou não na hipótese de incidência do art. 273 , §6 do CPC, é o conceito de "pedido incontroverso".

Literalmente, tem-se como definição aquilo que não é controverso; não admite ou não há discussões.

Nesta toada, para estar configurado o pedido incontroverso, bastaria que a parte contrária não manifestasse qualquer tipo de oposição.

Contudo, na prática, não deverá ser esta a regra da interpretação deste dispositivo.

Diz-se isto porque a ausência de oposição, de discussão sobre os pedidos inaugurais não pressupõe, necessariamente, êxito ao final. 


\section{VIANNAS SAPIENS}

edição especial

Juiz de Fora - 2014

Significa dizer que em algumas hipóteses, como por exemplo sentença improcedente, ausência de contestação, não haverá se falar efetivamente em existência de "controvérsia", sendo certo que o juiz poderá, inclusive, extinguir o processo sem resolução do mérito.

Para que haja a famigerada "incontrovérsia", capaz de ensejar o deferimento do pleito antecipatório, necessária se faz a presença de verossimilhança a ser analisada pelo juízo.

$\mathrm{Na}$ verdade, o incontroverso será caracterizado não por aquilo que não foi discutido, mas sim pelo que, a priori, é indiscutível.

Significa dizer que, mesmo apresentada a defesa, o juiz poderá conceder antecipação de tutela em razão de argumentos desarrazoados e sem propósito pela parte contrária; que mesmo sem defesa, poderá o juiz indeferir o requerimento antecipatório em razão da falta de características inerentes à antecipação de tutela, já expostas anteriormente.

Em resumo, de acordo com a definição de Teori Albino Zavascki (2013, p. 67), serão pressupostos para a antecipação de tutela prevista pelo parágrafo sexto do artigo em estudo: "pedido (ou a parcela dele) (a) não controvertido seriamente pelas partes, (b) verossímil e (c) cujo atendimento não está subordinado a qualquer questão prejudicial".

Para a corrente que admite a formação da coisa julgada nesta hipótese, tal apreciação é revestida de cognição exauriente pelo magistrado; sob a ótica da corrente contrária, a cognição é exauriente e reversível, não estando apta a se tornar imutável, pois está prevista em artigo destinado a tratar de forma específica a antecipação de tutela, sendo imprescindível a presença de verossimilhança, prova inequívoca, com caráter decisório provisório e precário, passível de revogação.

\section{RECENTE JULGADO DO SUPERIOR TRIBUNAL DE JUSTIÇA}

De acordo com o que se verifica, não há, hodiernamente, pacificação doutrinária ou jurisprudencial sobre a matéria. 
Em recente julgamento (REsp 1234887) ${ }^{3}$, a Terceira Turma do Superior Tribunal de Justiça se manifestou, em decisão unanime, no sentido de que não há se falar em cognição sumária na hipótese do art. 273, §6º̄, contudo, também não há a formação de coisa julgada.

Trata-se de uma ação de cobrança em que houve decisão que liberou o valor incontroverso de $\bigcup \$ 1,6$ milhão em favor de uma empresa de telecomunicação, de um total de US\$12,8 milhões depositados em juízo pela parte adversa.

O acórdão do Tribunal de Justiça do Rio de Janeiro teve por fundamento o parágrafo 6을 do artigo 273 do Código de Processo Civil.

No STJ, o Ministro Relator, Villas Bôas Cueva, afirmou que o objetivo do CPC é atender ao preceito constitucional da duração razoável do processo, inserindo o parágrafo $6^{\circ}$ no artigo 273 do CPC para permitir ao juiz deferir, em tutela antecipatória, parte incontroversa da demanda.

Prosseguiu em seu voto afirmando que:

a tutela antecipada, antes da reforma trazida pela Lei 10.444 , sempre foi vista como medida provisória, oriunda de cognição sumária, na qual o juiz realizava, para sua concessão, um juízo de verossimilhança da alegação, desde que houvesse prova inequívoca do direito alegado (...) enquanto nos demais casos de antecipação de tutela são indispensáveis os requisitos do perigo de dano, da aparência e da verossimilhança para a sua concessão, na tutela antecipada prevista no parágrafo $6^{\circ}$ do artigo 273 do CPC basta a incontrovérsia de uma parte dos pedidos".

Acrescentou, ainda, que "se um dos pedidos, ou parcela deles, já se encontra comprovado, confessado ou reconhecido, não há razão que justifique o seu adiamento até a decisão final que aprecie a parte controversa da demanda, que carece de instrução probatória".

Sustenta seu com argumento de que não há previsão legal que preveja a possibilidade de cisão da sentença. Via de consequência, não se admite sentenças

\footnotetext{
${ }^{3}$ http://www.stj.gov.br/portal stj/publicacao/engine.wsp?tmp.area=398\&tmp.texto=112036 Acesso em: $19 / 12 / 2013$
} 


\section{VIANNAS SAPIENS}

edição especial

Juiz de Fora - 2014

parciais, sendo a decisão oriunda do art. 273, §6 uma "decisão interlocutória de mérito".

Em outro ponto de seu voto, novamente o Ministro Relator afirma que a previsão do $\S^{\circ}$ do art. 273 do CPC pretende atender aos princípios constitucionais relacionados à efetividade da prestação jurisdicional, economia, tempo de duração do processo.

Vejam aqui que os argumentos despendidos pelo Ministro Villas Boas são deveras atraentes pois, se considerarmos que, de fato, deve-se buscar a celeridade na prestação jurisdicional, a antecipação de tutela em pedido incontroverso é um meio rápido e eficaz para se alcançar decisão final, ainda que parcialmente.

Apesar de não se concordar integralmente com a argumentação utilizada no referido acórdão, mormente quando se afirma que " a antecipação em comento não é baseada em urgência, nem muito menos se refere a um juízo de probabilidade, haja vista que incontroversa", o resultado final se coaduna com a posição final deste trabalho.

Isto porque Villas Boas conclui que "por questão de política legislativa, a tutela acrescentada pela Lei 10.444 não é suscetível de imunização pela coisa julgada".

De toda sorte, conclui-se que, de acordo com o que fora estudado, por certo a formação da coisa julgada nestes casos não ocorre por razões que ultrapassam mera questão de política legislativa.

Trata-se de precedente importante em nosso Tribunal Superior, contudo, longe de colocar uma "pá de cal" sobre a discussão.

\section{CONCLUSÃO}

Em que pese a coisa julgada ser protagonista em nosso sistema processual, consagrada como direito fundamental pela Constituição da República, contemplando a segurança jurídica no ordenamento jurídico, certamente não incidirá em toda e qualquer situação. 
Alguns dos argumentos apresentados no presente trabalho nos levam a crer que não há possibilidade de formação da coisa julgada nas hipóteses previstas pelo art. 273 do CPC, quando se tratar de tutela antecipatória caracterizada eminentemente por sua urgência.

Nessa hipótese, a decisão do magistrado será firmada por meio de cognição sumária e não exauriente, revestida de reversibilidade e precariedade, impossibilitando a formação de um juízo de certeza.

A maior discussão gira em torno do parágrafo sexto do supracitado artigo, quando prevê a possibilidade de antecipação de tutela nos casos em que restar incontroverso um ou mais pedidos. Seria esta decisão imutável? Qual sua natureza jurídica?

Como se pode observar (item 2.1), o tema não pacificado pela doutrina, já que parte dela afirma se tratar de 'equivoco topográfico' do legislador, enquanto doutro lado se encontra a afirmação de que não há se falar em coisa julgada pela ausência de cognição exauriente e consequente possibilidade de alteração da decisão.

É uma tarefa hercúlea chegar a uma conclusão, já que ambos os argumentos utilizados são bem estruturados e coesos.

Contudo, parece-nos mais acertada a corrente que afirma não haver possibilidade de formação de coisa julgada da decisão que conceder antecipação de tutela de um ou mais pedidos que se mostrarem incontroversos.

Por certo não se trata de resolução parcial do mérito conforme o estado do processo, pois, se assim o fosse, não estaria previsto na parte destinada às tutelas antecipatórias e não estaria passível de revogação.

Suas características são bem definidas e inevitavelmente contrárias àquelas que possibilitam a imutabilidade da decisão. Não há como se negar esta realidade.

Salto aos olhos alguns exemplos utilizados para afirmar se tratar de uma decisão definitiva, já que em sua maioria não se enquadram no dispositivo em comento, mas sim em outros que permitem, efetivamente, o julgamento conforme estado do processo, fracionando o julgamento. 
Se imaginarmos uma ação de cobrança, em que certo valor é "incontroverso" e o magistrado entender por bem resolver o mérito acerca deste valor, certamente estará se falando em julgamento do processo conforme seu estado (hipóteses previstas nos artigos 329 e seguintes do CPC), e não de tutela antecipada. Apenas se configuraria a antecipação de tutela se ainda não restasse plena certeza dos pleitos, se o juízo não tivesse se embasado em cognição exauriente e estaria, pois, apto a reverter sua decisão mediante novos fatos e argumentos.

Verifique-se que são casos específicos aqueles em que será aplicado o art. 273, §6º , não restando dúvidas que não se trata de resolução parcial de mérito, já que não há cognição exauriente e a decisão poderá ser modificada a critério e motivação do juízo frente a análise de fatos novos, devendo-se considerar, inclusive, o conhecimento superveniente de matérias de ordem pública.

Admitir in casu a formação de coisa julgada, seria o mesmo que permitir o julgamento de mérito sem a ideal formação do processo e seu regular andamento e exercício de profunda cognição pelo magistrado, bem como a irreversibilidade de uma decisão interlocutória, caracterizada como antecipação de tutela - o que vai de encontro com todo o estudo e previsão do referido instituto.

A coisa julgada nas antecipações de tutela, em qualquer hipótese, se formará não em decorrência desta, mas sim em decorrência de decisão, provavelmente sentença, que ratificará ou não aquela anteriormente proferida.

Importante se faz destacar que a imutabilidade das decisões judiciais, via de regra, decorrem de declarações suficientemente definitivas, ao passo que qualquer resquício de provisoriedade descarta qualquer possibilidade de definitividade da decisão.

Não se pretende com o presente estudo rechaçar a necessidade de segurança jurídica com a formação da coisa julgada, nem mesmo que esta se trata de característica da prestação jurisdicional; na verdade, o que se objetiva é o melhor entendimento das características essenciais para a sua formação que, a nosso entender, não estão presentes nos casos de tutela antecipada, principalmente a prevista pelo dispositivo objeto do estudo. 


\title{
EARLY AND PROTECTION (IN) EXISTENCE OF THING FOUND
}

\begin{abstract}
As stale, the preliminary injunction is derived, as a rule, a summary of the magistrate cognition and therefore be revoked later. However, no provision in the current Code of Civil Procedure, art. 273, § 6, that "injunctive relief may also be granted when one or more of the combined orders, or part of them, prove uncontroversial." On this premise, we begin discussions about whether or not the formation of res judicata due to the legal provision cited above. Starting from the assumptions governing the preliminary injunction, we analyze the divergent positions concerning training or not res judicata to the case for preliminary injunction request in uncontroversial. These positions will be analyzed in reliance on doctrine and homeland legislation and case analysis in a recent decision of the Superior Court of Justice - STJ.
\end{abstract}

KEY-WORDS: ADVANCE RELIEF. RES JUIDICATA. BRIEF COGNITION. UNCONTROVERSIAL.

\section{REFERÊNCIAS}

CARNEIRO, Athos Gusmão. Da antecipação de tutela. 5. ed. Rio de Janeiro: Forense, 2004, p. 35 e 36.

DIDIER JR., Fredie. Curso de Direito Processual Civil, vol. 2, 7. ed. Bahia: Editora Jus podivm, 2012. 
MARINONI, Luiz Guilherme. Tutela antecipatória, julgamento antecipado da lide e execução imediata da sentença. 2. ed. São Paulo: RT, 1998, p. 66-105.

MARINONI, Luiz Guilherme. ARENHART, Sérgio Cruz. Processo Cautelar . 4. ed. rev. e atual; São Paulo: RT, 2012.

NEVES, Daniel Amorim Assumpção. Manual de Direito Processual Civil.

Vol.Único, 5 ed. São Paulo: Método, 2013.

THEODORO JÚNIOR, Humberto. Curso De Direito Processual Civil, vol. 1, Ed Forense, Rio de Janeiro, 2007.

SUPERIOR TRIBUNAL DE JUSTIÇA:

http://www.sti.gov.br/portal sti/publicacao/engine.wsp?tmp.area $=398 \&$ tmp.texto $=112$ $\underline{036}$ Acesso em 01/2014.

ZAVASCKI, Teori Albino. Antecipação Da Tutela Em Face De Pedido Incontroverso. http://www.abdpc.org.br/abdpc/artigos/Teori\%20Zavascki(2)\%20formatado.pdf Acesso em: 01/2014. 